\author{
Jennifer E. LANSFord AND Rosario CEBALlo* \\ University of Michigan
}

Antonia AbBey** Wayne State University

Abigail J. Stewart* University of Michigan

\title{
Does Family Structure Matter? A Comparison of Adoptive, Two-Parent Biological, Single-Mother, Stepfather, and Stepmother Households
}

Using data from the National Survey of Families and Households, we compared quality of family relationships and well-being across five different family structures with a particular focus on adoptive households. Four theoretical perspectives, each emphasizing the importance of different factors in determining relationship quality and wellbeing, guided this work and led us to compare adoptive families with families that include two biological parents, single mothers, stepfathers, and stepmothers. We found the most support for the perspective stressing the importance of family processes that occur in all types of families, rather than family structure. Specifically, there were few family structure differences based on fathers' and children's reports, and structure differences in mothers' reports were no longer significant after

Center for Child and Family Policy, Box 90545, Durham, NC 27708-0545 (lansford@pps.duke.edu).

*Department of Psychology, University of Michigan, 525 East University, Ann Arbor, MI 48109.

**Department of Community Medicine, Wayne State University, 4201 St. Antoine, Detroit, MI 48201.

Key Words: adoption, family relationships, family structure, child and parent well-being. controlling for disagreements between family members. The implications of these results for adoption theory and policies are discussed.

In recent decades, demographic changes have altered the structure of American families. Researchers have investigated these changes in several ways, frequently by comparing a wide range of outcomes for children and parents in two-parent biological versus those in single-parent and stepparent families. Adoptive family structures also are an increasingly common family form. In previous research, adoptive families often have been compared with two-parent biological families. Adoptive families share certain features (e.g., lack of biological ties) with other types of families, however, and a key question raised by previous research is which families serve as appropriate comparisons in examining whether adoptive families look better, worse, or about the same as others.

This study examined associations between different family structures, with a special emphasis on families with an adopted child, and relationship quality and well-being for both parents and children. After briefly reviewing the adoption litera- 
ture, four different theoretical perspectives are described. Each theory leads to somewhat different hypotheses about how the experiences of adoptive families should be similar to, and different from, other family types and how these other family types should compare with one another.

\section{Overview of Adoption ReseARch}

A number of studies show that adoption is related to increased risk of academic difficulties, externalizing problem behavior, psychological maladjustment, and other negative outcomes (Haugaard, 1998; Wierzbicki, 1993). Many other studies reveal no significant differences between the adjustment of adopted and nonadopted children and adolescents, however (e.g., Borders, Black, \& Pasley, 1998). Recently the Search Institute surveyed a random sample of 1,262 parents, 881 adopted adolescents, and 78 nonadopted siblings and found that $74 \%$ of the adopted adolescents reported positive family dynamics (Benson, Sharma, \& Roehlkepartain, 1994). Moreover, adoptees' assessments of family characteristics such as level of warmth, communication, family harmony, and support matched reports by a national sample of nonadopted adolescents. In addition, 75\% of the adopted adolescents reported that their mental health was "very good" or "excellent," and 72\% were within normal ranges of internalizing and externalizing behaviors on Achenbach Youth SelfReport scales.

Researchers have devoted less attention to the study of adoptive parents. Coming to terms with the experience of infertility, handling an often intrusive adoption screening process, coping with societal stigmatization, and explaining adoption to their children are a few of the challenges adoptive parents may face (Benson et al., 1994; Brodzinsky, 1987). Nevertheless, adoptive parents do not appear to be more susceptible to negative adjustment and family problems than are other parents (Borders et al., 1998; Rosenberg, 1992).

Most research uses two-parent biological families rather than other common family forms as the basis of comparison for adoptive families. The current study investigates family structure differences in psychological well-being and the quality of adopted children's and adoptive parents' relationships at a single point in time by comparing them with family members in four other family configurations: (a) two-parent biological families, (b) single-mother families raising biological children following a divorce, (c) stepfather families, and (d) stepmother families. We propose and test the plausibility of four hypotheses that coincide with four theoretical perspectives commonly used to explain family structure differences in adjustment. These perspectives variously focus on social stigmatization, the presence of two adults in the household, biological ties, and family processes (vs. structure). Each perspective is described in more detail below.

\section{Stigmatization as the Key Factor}

Adoptees and their adoptive parents often face discrimination and stigmatization (Brodzinsky, 1987). According to Kressierer and Bryant (1996), adoptive relationships are often stigmatizing because of societal expectations that men and women would prefer to parent biological children. Thus, adoptive parents may question the legitimacy and authenticity of their parental roles (Miall, 1987). In addition, adoptees report experiencing discriminatory legal, social, and institutional practices such as receiving differential treatment in health care settings because of their lack of information about biological relatives' medical history (Kressierer \& Bryant). All of the other family structures investigated in this study involve at least one biological parent; thus, this theoretical perspective leads to the hypothesis that as the most stigmatized group, members of adoptive families will have lower well-being and poorer quality relationships (between parents and children, spouses, and siblings) than will members of other types of families.

\section{Socialization by Two Parents as Optimal}

According to socialization theories that hold the presence of two parents as vital for the optimal socialization of children, members of single-parent families are the most at-risk family structure group. Indeed, there is some evidence that children from single-mother homes continue to experience academic and social adjustment problems even years after their parents' divorce (Lindner, Hagan, \& Brown, 1992). Many researchers have posited that discrepancies in economic resources between single- and two-parent households may account for negative outcomes experienced by children in single-parent families (Demo \& Acock, 1996; Lamb, Sternberg, \& Thompson, 1999). Long-term single parenting often co-occurs with chronic stressors such as reduced access to instrumental and emotional supports and the re- 
sulting role strain (Thompson \& Ensminger, 1989). According to this perspective, adoptive families with two parents would not be expected to differ from other types of two-parent families.

\section{Divorce And Stepparent Research: The PRIMACY OF BIOLOGICAL TIES}

A large number of studies have documented that children in divorced and remarried families evince a host of negative problem behaviors in comparison to children from "intact" families. For example, children from divorced, single-parent, and remarried families may be more susceptible to externalizing and internalizing problems, low selfesteem, poor academic performance, relational difficulties, delinquent behavior, and substance abuse (Amato, 1993; Amato \& Keith, 1991). Researchers differ in their interpretations of these findings. Amato reviewed several perspectives that could account for children's negative adjustment to their parents' divorce and remarriage, including the absence of one of their biological parents, the difficult adjustment period for custodial parents, interparental conflict, economic hardship, and stressful life changes. There is evidence that stepparents navigate ambiguous insider-outsider roles within new family forms and that parentchild relationships in families without two biological parents are characterized by greater distance and conflict (Bray \& Berger, 1993; Coleman \& Ganong, 1997). Thus, based on this perspective, adoptive families would be indistinguishable from single-parent and stepparent families, but all of these family types would show less optimal functioning than two-parent biological families.

\section{The Influence of Family Processes}

Investigations of family process factors across different types of family structure are relatively rare (Borrine, Handal, Brown, \& Searight, 1991). Dunn, Deater-Deckard, Pickering, and O'Connor's (1998) finding that older children's adjustment following their parents' divorce did not differ from the adjustment of children in other family forms after taking into account the mother's adjustment, quality of the mother-child relationship, and other social risk indicators illustrates the value of examining structure and process simultaneously. Using a similar design to study adopted adolescents, Benson et al. (1994) found that mental health outcomes were predicted best by adolescents' ratings of family warmth. Additionally, regardless of fam- ily structure and divorce status, children in highconflict families experience more adjustment problems than do children in low-conflict families (Hetherington, Bridges, \& Insabella, 1998; Stewart, Copeland, Chester, Malley, \& Barenbaum, 1997; Vandewater \& Lansford, 1998). Finally, Demo and Acock (1996) studied adolescent wellbeing in four family structures and found that differences in adolescent well-being as a function of family structure were relatively minor, especially when compared with differences as a function of family process variables. These findings support the contention that family structure does not automatically adversely affect family members' well-being, a perspective that has gained wide support from family researchers in recent years. Based on this perspective, adoptive families would not be expected to differ in systematic ways from other types of families with regard to well-being and quality of social relationships.

\section{METHOD}

\section{Participants}

This study includes data from 799 families who were participants in the second wave of the National Survey of Families and Households (NSFH; Sweet \& Bumpass, 1996). The NSFH is a twowave panel study (Time 1 in 1987-1988; Time 2 in 1992-1994) of a randomly selected, nationally representative sample of adults aged 19 and older, oversampling for minorities, single-parent families, families with stepchildren, cohabiting couples, and recently married couples. The sample for this study includes families that participated in the second wave of data collection because at this time only, focal children between the ages of 10 and 18 years (randomly selected from among the children in the household) provided self-reports of their well-being and the quality of their relationships with family members. At least one parent from each household also was interviewed. Mothers and fathers were interviewed separately in face-to-face interviews, and focal children were interviewed over the telephone.

We focus on five different family structures present in this sample. These include households with at least one child 18 years of age or younger and with (a) two married parents and at least one adopted child ( $66 \%$ of focal children were adopted when they were younger than 1 year); (b) two married parents in which all children in the household are biological children of both parents; (c) a 
single mother who is single because she has divorced (rather than widowed or never married) with biological children only; (d) a mother biologically related to the children in the household and a stepfather to at least one of the children; (e) a father biologically related to the children in the household and a stepmother to at least one of the children. Because of the relatively smaller number of adoptive $(n=111)$ and stepmother $(n=88)$ households that met our selection criteria in the full NSFH compared with the other family structures, we randomly selected 200 families from each of the other three family structures to include in our sample. There were not enough single fathers to include this family structure group.

For the households in our sample, we have either reports from both parents in the household and the child, reports from one parent, reports from both parents, or reports from one parent and a child. We analyze reports from each respondent separately. The analyses have a three-tiered structure: (a) questions asked of mothers $(n=696)$ and fathers $(n=506)$ not focused on the focal child (e.g., parent's well-being, relationship with the spouse); (b) questions asked of mothers $(n=$ 402) and fathers $(n=261)$ regarding the focal child (e.g., parent report of the focal child's wellbeing and relationships); and (c) questions asked of 10-18-year-old focal children who fit the aforementioned criteria $(n=212)$.

\section{Measures}

Theoretical considerations and empirical verification through reliability, correlational, and factor analyses were used to create scales and conceptual clusters of the variables. For all measures described below, mothers' alpha is reported first and fathers' alpha second.

Parent well-being. A short form of the Center for Epidemiologic Studies Depression Scale (Radloff, 1977) comprised of 12 items rated on 7-point scales asking how many days in the last week the respondent had experienced affective and somatic symptoms such as sadness, loneliness, or a poor appetite was used to assess parent depressed affect $(\alpha=.93, .91)$. Parent self-esteem and efficacy were assessed using nine items from measures developed by Rosenberg (1965) and Pearlin, Meneghan, Lieberman, and Mullan (1981) in which parents rated on 5-point scales how much they agreed with statements such as whether they were satisfied with themselves and felt that they had control over things that happen to them $(\alpha=.80$, .80). Parent life satisfaction was assessed by a single question asking parents to rate how things are going these days on a 7-point scale.

Child well-being and adjustment. Parents completed an abbreviated version of the Child Behavior Checklist (Achenbach \& McConaughy, 1987). Scores (rated on a 3-point scale) were averaged to create two measures of child well-being: (a) child internalizing behavior ( 8 items; $\alpha=.75, .78$ ); and (b) child externalizing behavior (12 items; $\alpha=$ $.86, .88)$. An index of child problem behaviors was created using parents' reports of whether the focal child had ever been suspended or expelled from school, in trouble with the police, and whether the parent had met with a teacher or principal about the child's behavior problems in the last year. The total score on this scale was a sum of the number of these problems that the child experienced. Parents were asked what grades the focal child usually received in school. Finally, parents were asked how frequently the focal child has friends come to their home and how many of the focal child's friends the parent knows.

Child self-esteem and efficacy was measured by averaging children's reports on six items (rated on 4-point scales) from Rosenberg's (1965) and Pearlin and colleagues' (1981) self-esteem and control scales $(\alpha=.62)$. A single item was used to measure child life satisfaction by having them rate on a scale ranging from 0 to 10 how their life was going. Children were asked how often they smoke cigarettes, use marijuana, skip school without permission, and get into fights at school. Children also reported their grades in school. Children's involvement with their peers was assessed through a single item asking how often the child has friends come home and the sum of the number of hours per week the child is involved in extracurricular activities including sports, music, drama, student government, religious organizations, and community groups such as Scouts and 4-H.

Family relationships. Parents rated on a 7-point scale a single item assessing the overall quality of their relationship with their spouse. Parents' reports of satisfaction with the spouse in eight domains (understanding, love and affection, time together, demands, sexual relationship, money, work around the house, parenthood) were averaged to create a single scale (items rated on 7-point scales; $\alpha=.88, .90)$. A scale reflecting disagreements with spouse was created by averaging six items 
(on 6-point scales) asking parents how often in the past year they had open disagreements with their spouse about household tasks, money, spending time together, sex, in-laws, and the children $(\alpha=.79, .80)$.

Four measures were used to assess parents' views of their focal child's family relationships. A single item was used to measure the overall quality of the parent's relationship with the focal child (rated on an 11-point scale). Six items on 6-point scales were averaged to create a scale reflecting how often in the last 3 months the parent and focal child had open disagreements about how the child dresses, friends, helping around the house, schoolwork, getting along with other family members, and money $(\alpha=.64, .69)$. Three items were standardized and averaged to create a scale to assess the quality of the focal child's relationship with grandparents (rated on 6-point scales) and an 11point rating of how close the focal child was with the grandparents $(\alpha=.71, .81)$. In addition, parents rated (on a 5-point scale) how well their children get along with each other compared with other families they know.

Focal children reported on their relationships with mothers, fathers, and siblings. A scale reflecting the quality of the focal child's relationship with the mother or stepmother in the household was created by standardizing and averaging four items (on 5-point scales) asking how often the mother praises the child, criticizes the child, how likely the child would be to go to the mother if he or she had a major decision to make or was feeling depressed, one presence-absence item assessing whether the child spent time alone with the mother in the past week, and two items rating on 11-point scales how much the child admires the mother and the overall quality of the relationship $(\alpha=.77)$. A comparable scale was created to reflect the quality of relationship with the father or stepfather in the household by standardizing and averaging identical items asked about the father $(\alpha=.83)$. If the child had siblings, a measure of quality of relationship with siblings was created by standardizing and averaging three items regarding how likely the child would be to talk to siblings if he or she had a major decision to make or was depressed (each rated on a 5-point scale) and how well the child and siblings get along compared with other families $(\alpha=.68)$.

Family climate. Parents reported their overall satisfaction with family life using a single item rated on a 7-point scale. Time with the children was measured through six items that were standardized and averaged to create a scale. Parents were asked how often they spend time with the children in leisure activities away from home, at home working or playing together, having private talks, helping with reading or homework, and watching television or videos (each rated on a 6-point scale) and how many days in the last week the whole family ate dinner together $(\alpha=.73, .80)$. Family cohesion was measured using three items from Rossi and Rossi's (1990) scale averaged with two items created by the NSFH research team. Specifically, parents indicated on 4-point scales whether their family has fun together, things are tense and stressful in the family (reverse coded), family members show concern and love for each other, family members feel distant and apart from each other (reverse coded), and whether the family works well as a team $(\alpha=.81, .86)$.

Parental monitoring of children was assessed by averaging children's reports of three items asking how much their parents know about who they spend their time with, what they do in their free time, and how they spend their money (each on a 5-point scale; $\alpha=.73$ ). Children's reports on two items asking how they feel about getting married and having children in the future were averaged to create a scale measuring children's thoughts about having a family in the future (items rated on 4-point scales; $\alpha=.74)$. Children completed the same measure of family cohesion completed by their parents $(\alpha=.71)$.

\section{Demographic Variables}

To control for confounding influences that may affect associations among family structure and outcome measures, we used several demographic covariates including (a) economic status of the family as measured by the ratio of family income to that family's poverty threshold income, (b) number of years of education completed by the mother, (c) length of time the parents had been in their present marital status, (d) number of hours per week the mother works outside the home. When examining parents' reports, we controlled for age of the parent. In analyses of parents' reports of the focal child and the child's self-reports, we controlled for the child's age and gender. Because parents' own well-being may influence reports of their children's well-being, in analyses of the parent's reports of the child's well-being, we controlled for the parent's score on the Center for Epidemiologic Studies Depression Scale and par- 
ent's life satisfaction. Parent's race (child's race was not assessed), age of the youngest child, and number of children in the household were considered as potential control variables, but preliminary analyses revealed that family structure groups did not differ with regard to these variables, and they were not included in subsequent analyses. Preliminary analyses indicated that children who were adopted before the age of 1 year differed from those adopted when they were 1 year or older on only 3 of 53 possible well-being and relationshipquality variables. Thus, age of adoption was not used in further analyses.

\section{RESUltS}

\section{Family Structure Differences: Mother Reports}

MANCOVAs of each of the eight conceptual groupings based on mothers' reports by family structure (five groups) were conducted. The overall MANCOVA was significant for five of these eight tests: (a) mother's well-being [Pillai's $F(12$, $\left.1,722)=2.36, p<.01, \eta^{2}=.02\right]$, (b) child's well-being [Pillai's $F(12,993)=2.27, p<.01$, $\eta^{2}=.03$ ], (c) child's friendships [Pillai's $F(8$, $\left.668)=4.04, p<.001, \eta^{2}=.05\right]$, (d) child's family relationships [Pillai's $F(12,1,095)=3.40$, $p<.001, \eta^{2}=.04$ ], and (e) family life [Pillai's $\left.F(12,1,584)=3.34, p<.001, \eta^{2}=.03\right]$. The family structures did not differ on mothers' reports of the (a) child's school grades $[F(4,183)$ $=1.10, n s]$, (b) relationship with the spouse (using four groups only because these items did not apply for single mothers) [Pillai's $F(9,1,476)=$ $.94, n s]$, or (c) sibling relationship quality $[F(4$, 497) $=.09, n s]$.

Follow-up univariate $F$ tests of the individual scales in the MANCOVAs are presented in Table 1. There were significant family structure differences on 12 of the 19 variables examined. The hypothesis suggesting that adoptive families will have the most problems because of stigmatization was partially supported. Specifically, adoptive mothers reported that their child had more internalizing and externalizing problems and that they had more disagreements with their child than did mothers in two-parent biological, stepfather, or stepmother households. The hypothesis based on the perspective that two-parent families are optimal also was partially supported. In particular, single mothers reported more depressed affect, lower self-esteem and efficacy, and lower life satisfaction than did other mothers. The third perspective, that two bi- ological parents are optimal, was supported in that mothers in these families reported that their child had fewer internalizing, externalizing, and problem behaviors. For mothers' reports of their marital relationship, children's school grades, children's sibling relationships, and for several measures within constructs where there were overall significant effects of structure, a lack of family structure differences offers preliminary support for the fourth perspective advocating the importance of family processes rather than family structure. For some constructs, structure differences not predicted by any of these perspectives were found. Thus, mothers' data do not clearly support one specific hypothesis.

\section{Family Structure Differences: Father Reports}

MANCOVAs of each of the eight conceptual groupings based on fathers' reports by family structure (four groups because father reports were not available for the single-mother households) were conducted. The overall MANCOVA was significant for three of these eight tests: (a) child's friendships [Pillai's $F(6,430)=2.64, p<.05, \eta^{2}=$ .04], (b) child's family relationships [Pillai's $F(9$, $\left.696)=3.06, p<.01, \eta^{2}=.04\right]$, and (c) family life [Pillai's $F(9,1,116)=2.42, p<.05, \eta^{2}=$ $.02]$. There were no significant differences by family structure in (a) father's well-being [Pillai's $F(9$, $1,236)=.74, n s]$, (b) child's well-being [Pillai's $F(9,621)=.53, n s]$, (c) child's grades in school $[F(3,111)=1.78, n s]$, (d) relationship with the spouse [Pillai's $F(9,1,374)=.87, n s]$, or (e) sibling relationship quality $[F(3,366)=.05, n s]$.

Table 2 shows follow-up univariate tests and descriptive statistics for each family structure group. Families differed on 3 of the 19 variables examined. These differences were not consistent with either the adoption as stigmatizing or socialization by two parents as optimal perspectives. Consistent with the perspective emphasizing the primacy of biological ties with two parents, fathers from twoparent biological households reported spending more time with their children and higher family cohesion than did fathers in other households. Given how few differences were found, fathers' data do not support the hypothesis that one family structure is better or worse than others, providing implicit support for the process hypothesis.

\section{Family Structure Differences: Child Reports}

To avoid limiting analyses to children with a mother, father, and siblings in the household, AN- 


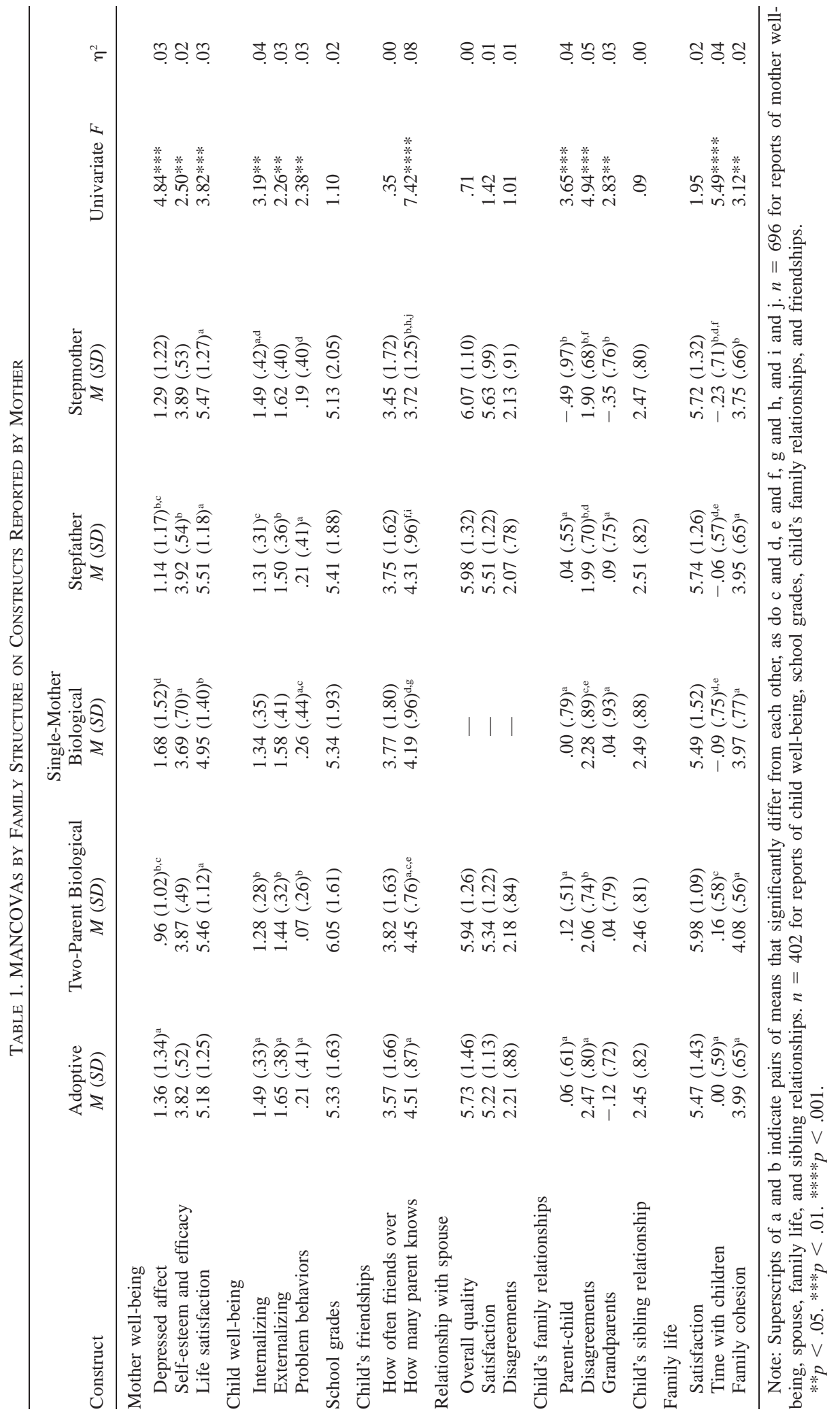


Table 2. MANCOVAs by Family Structure on Constructs Reported by Father

\begin{tabular}{|c|c|c|c|c|c|c|}
\hline Construct & $\begin{array}{l}\text { Adoptive } \\
M(S D)\end{array}$ & $\begin{array}{c}\text { Two-Parent } \\
\text { Biological } \\
M(S D)\end{array}$ & $\begin{array}{l}\text { Stepfather } \\
M(S D)\end{array}$ & $\begin{array}{c}\text { Stepmother } \\
M(S D)\end{array}$ & Univariate $F$ & $\eta^{2}$ \\
\hline \multicolumn{7}{|l|}{ Father well-being } \\
\hline Depressed affect & $1.04(1.18)$ & $.89(1.03)$ & $.99(1.02)$ & $.88(1.04)$ & 1.34 & .01 \\
\hline Self-esteem and efficacy & $3.89(.56)$ & $3.92(.58)$ & $3.86(.54)$ & $3.89(.54)$ & .61 & .01 \\
\hline Life satisfaction & $5.24(1.13)$ & $5.43(1.12)$ & $5.34(1.27)$ & $5.51(1.21)$ & .82 & .01 \\
\hline \multicolumn{7}{|l|}{ Child well-being } \\
\hline Internalizing & $1.43(.37)$ & $1.32(.32)$ & $1.45(.40)$ & $1.41(.41)$ & 60 & .01 \\
\hline Externalizing & $1.64(.36)$ & $1.51(.39)$ & $1.65(.42)$ & $1.66(.40)$ & 1.14 & .02 \\
\hline Problem behaviors & $.23(.43)$ & $.11(.31)$ & $.18(.39)$ & $.19(.40)$ & .36 & .01 \\
\hline School grades & $5.04(1.87)$ & $6.22(1.74)$ & $5.44(2.17)$ & $5.48(1.65)$ & 1.77 & .05 \\
\hline \multicolumn{7}{|l|}{ Child's friendships } \\
\hline How often friends over & $3.23(1.44)$ & $3.85(1.64)$ & $3.95(1.52)$ & $3.25(1.69)$ & $2.34 *$ & .03 \\
\hline How many parent knows & $3.89(1.28)$ & $3.74(1.08)$ & $3.56(1.10)$ & $3.71(1.18)$ & $2.57 *$ & .04 \\
\hline \multicolumn{7}{|l|}{ Relationship with spouse } \\
\hline Overall quality & $5.74(1.45)$ & $5.79(1.22)$ & $5.94(1.30)$ & $5.99(1.17)$ & .17 & .00 \\
\hline Satisfaction & $5.41(1.07)$ & $5.31(1.13)$ & $5.51(1.05)$ & $5.60(1.02)$ & .25 & .00 \\
\hline Disagreements & $2.20(.84)$ & $2.22(.86)$ & $2.16(.82)$ & $2.31(.96)$ & 1.14 & .01 \\
\hline \multicolumn{7}{|l|}{ Child's family relationships } \\
\hline Parent-child & $.01(.65)$ & $.20(.56)$ & $-.22(.77)$ & $-.09(.63)$ & 1.39 & .02 \\
\hline Disagreements & $1.91(.48)$ & $1.88(.74)$ & $1.82(.72)$ & $2.20(.86)$ & 2.43 & .03 \\
\hline Grandparents & $-.18(.78)^{\mathrm{a}}$ & $.22(.78)^{\mathrm{c}}$ & $-.27(.82)^{\mathrm{a}, \mathrm{d}}$ & $.32(.77)^{\mathrm{b}, \mathrm{c}}$ & $6.72 * * * *$ & .08 \\
\hline Child's sibling relationship & $2.50(.76)$ & $2.46(.94)$ & $2.55(.84)$ & $2.46(.79)$ & .05 & .00 \\
\hline \multicolumn{7}{|l|}{ Family life } \\
\hline Satisfaction & $5.64(1.13)$ & $5.92(1.05)$ & $5.82(1.35)$ & $5.76(1.12)$ & .98 & .01 \\
\hline Time with children & $-.11(.65)^{\mathrm{a}}$ & $.19(.66)^{\mathrm{b}}$ & $-.17(.71)^{\mathrm{a}}$ & $.03(.66)$ & $4.58 * * *$ & .04 \\
\hline Family cohesion & $3.85(.67)^{\mathrm{a}}$ & $4.13(.62)^{\mathrm{b}}$ & $3.86(.66)^{\mathrm{a}}$ & $3.89(.57)^{\mathrm{a}}$ & $4.92 * * *$ & .04 \\
\hline
\end{tabular}

Note: Superscripts of $\mathrm{a}$ and $\mathrm{b}$ and of $\mathrm{c}$ and $\mathrm{d}$ indicate pairs of means that significantly differ from each other. $n=506$ for reports of father well-being, spouse, family life, and sibling relationships. $n=261$ for reports of child well-being, school grades, child's family relationships, and friendships.

$* p<.10$. *** $p<.01$. **** $p<.001$

COVAs (rather than MANCOVAs) were used to examine family structure differences in focal children's reports of their relationships with their mother, father, and siblings. There were no family structure differences in the quality of children's relationships with their mothers $[F(4,182)=$ $1.11, n s]$ or siblings $[F(4,175)=.49, n s]$. Children in households with a stepfather reported lower quality relationships with their (step) father than did children in adoptive, two-parent biological, or stepmother households, however $[F(3$, 128) $\left.=5.27, p<.01, \eta^{2}=.11\right]$.

MANCOVAs were used to analyze family structure differences in children's reports of the other conceptual groupings. There was a family structure difference in family life [Pillai's $F(12$, $\left.543)=3.13, p<.001, \eta^{2}=.07\right]$, specifically with regard to thoughts about having a family in the future. Adopted children were more likely to want to marry and have children in the future than were children in two-parent biological, singlemother, stepfather, or stepmother households. There were no structure differences in (a) child well-being [Pillai's $F(8,402)=.31, n s]$, (b) problem behaviors [Pillai's $F(16,800)=1.40, n s]$, (c) grades in school $[F(4,199)=.47, n s]$, or $(\mathrm{d})$ friendships [Pillai's $F(8,402)=1.20, n s]$. See Table 3 for follow-up univariate tests and descriptive statistics by family structure. Children significantly differed by family structure on 2 of the 15 variables examined. These differences (and lack of differences) were not consistent with predictions based on perspectives emphasizing the importance of stigmatization, socialization by two parents, or the primacy of biological ties.

\section{Family Structure, Processes, and Well-Being}

Thus far, we have found evidence for the process hypothesis through null results. To provide a more 


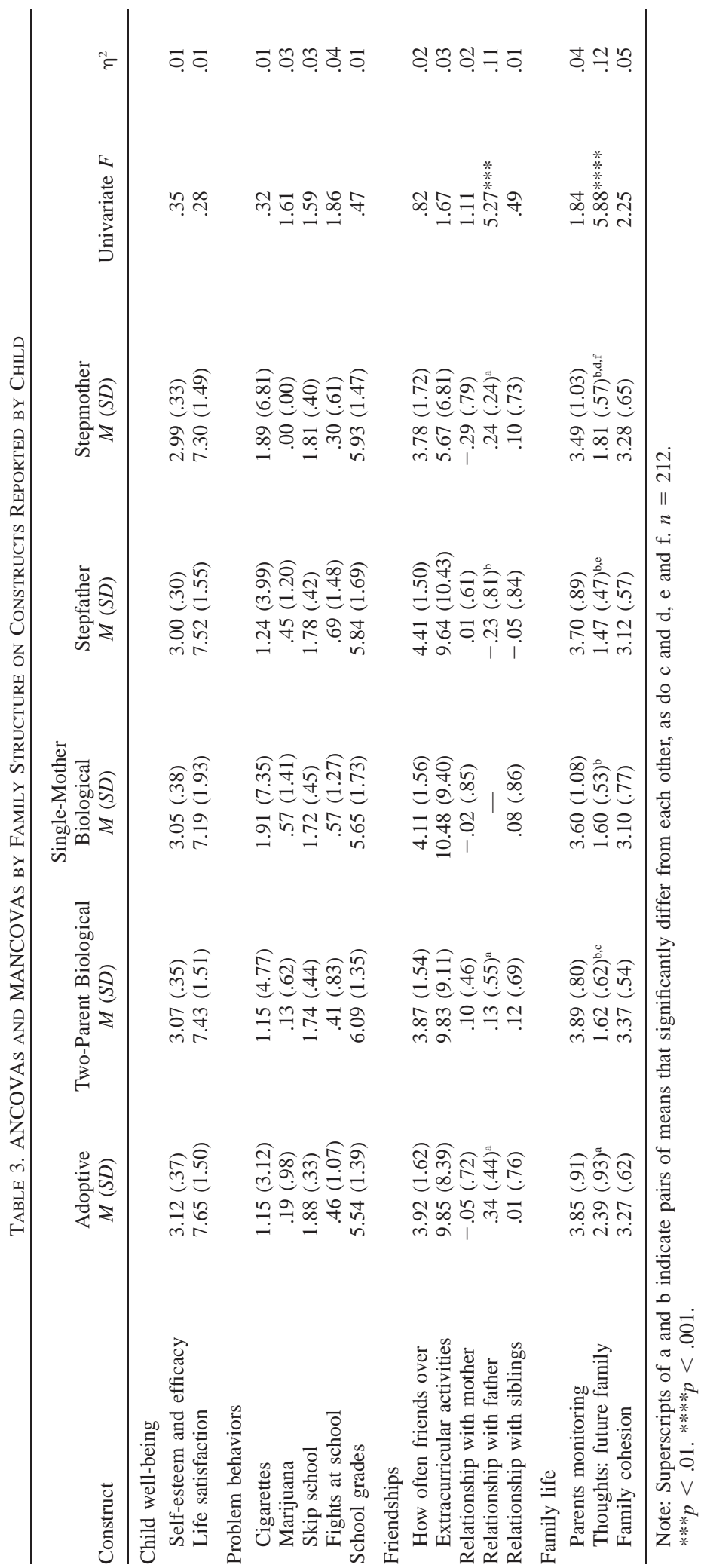


direct test of the fourth perspective regarding the importance of family processes, we conducted MANCOVAs with mothers' reports of their own well-being and their child's well-being as dependent variables. We did not conduct these analyses for fathers' or children's reports because their reports of well-being did not differ by family structure. We used identical sets of independent variables as in our previous analyses with the addition of two family process variables that have been found to be important in previous research-disagreements between spouses (e.g., Hetherington et al., 1998) and disagreements between parents and children (Stattin \& Klackenberg, 1992) —as additional control variables. Single-mother families were excluded from these analyses because they did not have reports of conflict with a spouse. After controlling for these family process variables, there were no longer significant family structure differences in mothers' well-being [Pillai's $F(9$, $732)=1.36, n s]$ or in mothers' reports of their children's well-being [Pillai's $F(9,705)=1.77$, $n s]$, supporting the fourth perspective that processes occurring within families are important determinants of well-being regardless of family structure.

\section{DISCUSSION}

Our goal was to investigate the importance of family structure in predicting psychological wellbeing and relational quality of family members in five different family configurations. Four theoretical perspectives led to hypotheses about whether these families would differ from one another and, if so, how they would differ.

One perspective is that stigmatization is the key factor leading to poor developmental outcomes (see Brodzinsky, 1987). As the most stigmatized group due to their lack of biological ties, adoptive families would be expected to show lower well-being and poorer relationship quality than would the other family structure groups, and twoparent biological families would be expected to look the most well adjusted. We found limited support for this hypothesis. Adoptive mothers reported that their children had the most externalizing problems, and mothers in two-parent biological families reported the fewest. Adoptive mothers reported having more disagreements with their children than did other mothers, but mothers in both stepmother and stepfather families reported fewer disagreements than did mothers in twoparent biological families. Thus, on some moth- ers' reports, adopted children appear to be at a disadvantage, but children from two-parent biological families did not always look best. Furthermore, adoptive families appear to be at an advantage on some measures. For example, adoptive mothers reported spending more time with their children and having higher family cohesion than did mothers in three of the four other family structures.

The second perspective is that socialization by two parents is optimal (Demo \& Acock, 1996). If this were the case, one would expect single-parent families to look worse than the other four family types with demographic controls. We found that single mothers had somewhat lower well-being than did married mothers. They did not differ in consistent ways from other families, and children in single-mother households did not report any differences in well-being or relationships compared with children in other types of families.

The third perspective emphasizes the primacy of biological ties with two parents (Amato \& Keith, 1991; Hetherington et al., 1998). Based on this perspective one would expect that single-parent, stepparent, and adoptive families would all be at a disadvantage compared with families that have two married parents living only with their biological children. Our findings provide only limited support for this perspective. Mothers in two-parent biological families reported that their children had fewer behavior problems (but did not differ from stepmothers' reports) and spent more time with their children (but did not differ from adoptive mothers' reports) than did mothers in other types of families. In addition, fathers in twoparent biological families reported spending more time with their children and having higher family cohesion than did fathers in all other types of families. These were the only indices that differed, as would be predicted by this perspective.

The final perspective stresses the importance of family processes in all family structures and posits that family structure per se is comparatively unimportant in predicting well-being and relationship quality (e.g., Dunn et al., 1998; Stewart et al., 1997). Indeed, fathers from different family structures did not differ in their reports of their own well-being, child's well-being, child's school grades, relationship with spouse, child's family relationships, or child's friendships. In addition, children from different family structures did not differ in their reports of well-being, problem behaviors, school grades, relationships with mothers, relationships with siblings, or friendships. Moth- 
ers' reports of child's school grades, relationship with spouse, child's sibling relationships, and child's friendships did not differ by family structure. Consistency among different reporters from the same family strengthens the evidence that these constructs, particularly children's school grades, sibling relationships, and friendships, do not differ substantially by family structure. Furthermore, family structure differences in mothers' well-being and mothers' reports of their child's well-being were no longer significant after controlling for family process variables.

To summarize, we found the most support for the perspective suggesting that processes occurring in all types of families are more important than family structure in predicting well-being and relationship outcomes. This was especially true for fathers' and children's reports. The pattern of findings based on mothers' reports was more complex, but after controlling for disagreements between spouses and between mothers and children, family structure differences in well-being were no longer significant.

Using responses from multiple reporters in the same family to measure well-being and relationship quality is an important strength of our study. Previous research provides some evidence that judgments of different family members about factors such as family cohesion and parental behaviors are sometimes quite different (Tein, Roosa, \& Michaels, 1994). In our study, there were clearly more family structure differences based on mothers' reports than on either fathers' or children's reports. It is possible that adoptive mothers, single mothers, and mothers in families with a stepparent are especially sensitive to any signs of problems because of cultural expectations that these types of families are more susceptible to problems than are two-parent biological families. It could also be the case that mothers are accurate in their assessments and that fathers and children tend to deny problems. These are tentative speculations, and a task for future researchers will be to investigate further the reasons for discrepancies in different family members' reports of well-being and family relationships.

In addition to providing information about children's lives, our study also makes an important contribution by addressing parents' well-being and relationships. Including parental well-being provides a more complete picture of how different types of families are faring. Moreover, many early studies of adoptive families relied on clinically based populations and typically lacked control groups or employed poorly matched controls, small sample sizes, and limited numbers of outcome measures with questionable reliability and validity (Brodzinsky, 1987). Our study represents an advance over the methodological shortcomings of this early work.

Our study has limitations as well. In particular, we did not have access to information about the circumstances preceding the adoptions. Recent federal policies have promoted adoptions from more diverse populations than was common in the past (e.g., children who are older, are from other countries, have disabilities, were abused or neglected before placement). Because children with special needs may bring more developmental and behavioral problems with them to their adoptive families, these children may have worse outcomes following adoption than would children from more traditional placements (i.e., infants with healthy birthmothers). In our sample, children adopted before the age of 1 year did not differ substantively from those adopted when they were 1 year or older. Nevertheless, we cannot draw conclusions about causality and directions of effects from our cross-sectional data. Longitudinal measures would help disentangle effects of family structure versus family process on relationship quality and well-being over time.

A key direction for future research, therefore, will be to investigate links between family processes, relationship quality, and well-being within and across family structures. Our findings suggest that adoption, divorce, and remarriage are not necessarily associated with the host of adjustment problems that have at times been reported in the clinical literature. What factors promote resilience in families despite these stressors? As profound demographic changes continue to reconfigure American families, future research should concentrate on elucidating factors beyond family structure that contribute to relationship quality and well-being of parents and children. It is not enough to know that an individual lives in a particular family structure without also knowing what takes place in that structure.

\section{Note}

The National Survey of Families and Households was funded by Grant HD21009 from the Center for Population Research at NICHD. This study was catalyzed by our participation in the Adoption, Infertility, and Gender Study Group at the Institute for Research on Women and Gender at the University of Michigan. The group (including Kristine Freeark, Sally Haslanger, Leslie Hollingsworth, Pamela Ramseyer, Nancy Reame, and Eli- 
nor Rosenberg) offered us stimulating discussions of the issues explored here, as well as feedback on our analyses and an early version of the manuscript.

\section{REFERENCES}

Achenbach, T. M., \& McConaughy, S. H. (1987). Empirically based assessment of child and adolescent psychopathology. Newbury Park, CA: Sage.

Amato, P. R. (1993). Children's adjustment to divorce: Theories, hypotheses, and empirical support. Journal of Marriage and the Family, 55, 23-38.

Amato, P. R., \& Keith, B. (1991). Parental divorce and the well-being of children: A meta-analysis. Psychological Bulletin, 110, 26-46.

Benson, P. L., Sharma, A. R., \& Roehlkepartain, E. C. (1994). Growing up adopted: A portrait of adolescents and their families. Minneapolis, MN: Search Institute.

Borders, L. D., Black, L. K., \& Pasley, B. K. (1998). Are adopted children and their parents at greater risk for negative outcomes? Family Relations, 47, 237241.

Borrine, M. L., Handal, P. J., Brown, N. Y., \& Searight, H. R. (1991). Family conflict and adolescent adjustment in intact, divorced, and blended families. Journal of Consulting and Clinical Psychology, 59, 753755.

Bray, J. H., \& Berger, S. H. (1993). Developmental issues in stepfamilies research project: Family relationships and parent-child interactions. Journal of Family Psychology, 7, 76-90.

Brodzinsky, D. M. (1987). Adjustment to adoption: A psychosocial perspective. Clinical Psychology Review, 7, 25-47.

Coleman, M., \& Ganong, L. H. (1997). Stepfamilies from the stepfamily's perspective. Marriage and Family Review, 26, 107-121.

Demo, D. H., \& Acock, A. C. (1996). Family structure, family process, and adolescent well-being. Journal of Research on Adolescence, 6, 457-488.

Dunn, J., Deater-Deckard, K., Pickering, K., \& O'Connor, T. G. (1998). Children's adjustment and prosocial behaviour in step-, single-parent, and nonstepfamily settings: Findings from a community study. Journal of Child Psychology \& Psychiatry, 39, 1083-1095.

Haugaard, J. J. (1998). Is adoption a risk factor for the development of adjustment problems? Clinical Psychology Review, 18, 47-69.

Hetherington, E. M., Bridges, M., \& Insabella, G. M. (1998). What matters? What does not? Five perspectives on the association between marital transitions and children's adjustment. American Psychologist, 53, 167-184.

Kressierer, D. K., \& Bryant, C. D. (1996). Adoption as deviance: Socially constructed parent-child kinship as a stigmatized and legally burdened relationship. De- viant Behavior: An Interdisciplinary Journal, 17, 391-415.

Lamb, M. E., Sternberg, K. J., \& Thompson, R. A. (1999). The effects of divorce and custody arrangements on children's behavior, development, and adjustment. In M. E. Lamb (Ed.), Parenting and child development in "nontraditional" families (pp. 125135). Mahwah, NJ: Erlbaum.

Lindner, M. S., Hagan, M. S., \& Brown, J. C. (1992). The adjustment of children in nondivorced, divorced single-mother, and remarried families. Monographs of the Society for Research in Child Development, 57 (2-3), 35-72.

Miall, C. E. (1987). The stigma of adoptive parent status: Perceptions of community attitudes toward adoption and the experience of informal social sanctioning. Family Relations, 36, 34-39.

Pearlin, L. I., Meneghan, E. G., Lieberman, M. A., \& Mullan, J. T. (1981). The stress process. Journal of Health and Social Behavior, 22, 337-356.

Radloff, L. S. (1977). The CES-D scale: A self-report depression scale for research in the general population. Applied Psychological Measurement, 1, 385401.

Rosenberg, E. B. (1992). The adoption life cycle: The children and their families through the years. New York: Free Press.

Rosenberg, M. (1965). Society and the adolescent selfimage. Princeton, NJ: Princeton University Press.

Rossi, A., \& Rossi, P. (1990). Of human bonding. New York: Aldine de Gruyter.

Stattin, H., \& Klackenberg, G. (1992). Discordant family relations in intact families: Developmental tendencies over 18 years. Journal of Marriage and the Family, 54, 940-956.

Stewart, A. J., Copeland, A. P., Chester, N. L., Malley, J. E., \& Barenbaum, N. B. (1997). Separating together: How divorce transforms families. New York: Guilford Press.

Sweet, J. A., \& Bumpass, L. L. (1996). The National Survey of Families and Households-Waves 1 and 2: Data description and documentation. Center for Demography and Ecology, University of WisconsinMadison.

Tein, J. Y., Roosa, M. W., \& Michaels, M. (1994). Agreement between parent and child reports on parental behaviors. Journal of Marriage and the Family, 56, 341-355.

Thompson, M. S., \& Ensminger, M. E. (1989). Psychological well-being among mothers with school age children: Evolving family structures. Social Forces, 67, 715-730.

Vandewater, E. A., \& Lansford, J. E. (1998). Influences of family structure and parental conflict on children's well-being. Family Relations, 47, 323-330.

Wierzbicki, M. (1993). Psychological adjustment of adoptees: A meta-analysis. Journal of Clinical Child Psychology, 22, 447-454. 